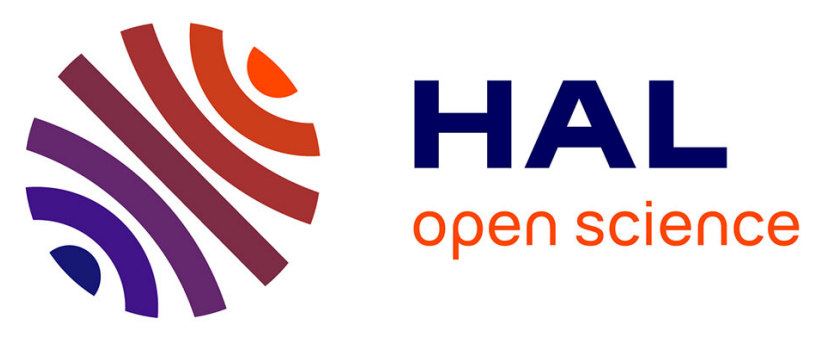

\title{
Amphiphilic copolymers based on polyoxazoline and grape seed vegetable oil derivatives: Self-assemblies and dynamic light scattering
}

Christophe Travelet, Mylene Stemmelen, Vincent Lapinte, Frédéric Dubreuil, Jean Jacques Robin, Redouane Borsali

\section{To cite this version:}

Christophe Travelet, Mylene Stemmelen, Vincent Lapinte, Frédéric Dubreuil, Jean Jacques Robin, et al.. Amphiphilic copolymers based on polyoxazoline and grape seed vegetable oil derivatives: Self-assemblies and dynamic light scattering. Journal of Nanoparticle Research, 2013, 15, pp.1626. 10.1007/s11051-013-1626-1 . hal-00924809

\section{HAL Id: hal-00924809 \\ https://hal.science/hal-00924809}

Submitted on 7 Jan 2014

HAL is a multi-disciplinary open access archive for the deposit and dissemination of scientific research documents, whether they are published or not. The documents may come from teaching and research institutions in France or abroad, or from public or private research centers.
L'archive ouverte pluridisciplinaire HAL, est destinée au dépôt et à la diffusion de documents scientifiques de niveau recherche, publiés ou non, émanant des établissements d'enseignement et de recherche français ou étrangers, des laboratoires publics ou privés. 


\section{Amphiphilic copolymers based on polyoxazoline and grape seed vegetable oil derivatives: Self-assemblies and dynamic light scattering}

\section{Christophe Travelet, ${ }^{*, a}$ Mylène Stemmelen, ${ }^{b}$ Vincent Lapinte, ${ }^{\text {b }}$ Jean- Jacques Robin, ${ }^{\mathrm{b}}$ Frédéric Dubreuil, and Redouane Borsali*,a}

${ }^{a}$ Centre de Recherches sur les Macromolécules Végétales (CERMAV - UPR 5301 CNRS), domaine universitaire de Grenoble, 601 rue de la Chimie, BP 53, 38041 Grenoble cedex 9, France $\dagger$

${ }^{\mathrm{b}}$ Institut Charles Gerhardt Montpellier (UMR 5253 CNRS - UM2 - UM1 - ENSCM), équipe ingénierie et architectures macromoléculaires, université de Montpellier II, cc 1702, place Eugène Bataillon, 34095 Montpellier cedex 5, France

$\dagger$ Affiliated with the Université Joseph Fourier (UJF), member of the Institut de Chimie Moléculaire de Grenoble (ICMG, FR 2607 CNRS), member of the PolyNat Carnot institute and member of the Arcane LabEx

* Corresponding authors: Christophe.Travelet@ cermav.cnrs.fr, Borsali@cermav.cnrs.fr. Telephone: +33 (0)4 760376 90, +33 (0)4 760376 40. Fax: +33 (0)4 76547203

Received date (to be automatically inserted after your paper is accepted if required according to the journal that you are submitting your paper to)

\section{Keywords:}

Amphiphilic copolymer; polyoxazoline; grape seed vegetable oil; self-assembly; selforganization; nanoparticle; dynamic light scattering.

\section{Abstract:}


The behavior in solution of original structures of amphiphilic partially natural copolymers based on polyoxazoline (POx) (poly(2-methyl-2-oxazoline)) and grape seed vegetable oil derivatives (linear, T- and trident-structure) are investigated. The results show that such systems are found,using dynamic light scattering (DLS), to spontaneously self-organize into monomodal, narrow-size and stable nanoparticles in aqueous medium. The obtained hydrodynamic diameters $\left(D_{h}\right)$ range from 8.6 up to $32.5 \mathrm{~nm}$. Specifically, such size increases strongly with increasing natural block (i.e. lipophilic species) length due to higher hydrophobic interactions (from $10.1 \mathrm{~nm}$ for $\mathrm{C}_{19}$ to $19.2 \mathrm{~nm}$ for $\mathrm{C}_{57}$ ). Furthermore, increasing the polyoxazoline (i.e. hydrophilic block) length leads to a moderate linear increase of the $\mathrm{D}_{\mathrm{h}^{-}}$ values. Therefore, the first order size effect comes from the natural lipophilic block whereas the characteristic size can be tuned more finely (i.e. in a second order) by choosing appropriately the polyoxazoline length. The DLS results in terms of characteristic size are corroborated using nanoparticle tracking analysis (NTA), and also by atomic force microscopy (AFM) and transmission electron microscopy (TEM) imaging where welldefined, spherical and individual nanoparticles exhibit a very good mechanical resistance upon drying. Moreover, changing the lipophilic block architecture from linear to T-shape and keeping the same molar mass generates a branching and thus a shrinking by a factor of 2 of the nanoparticle volume, as shown by DLS. In this paper, we clearly show that the selfassemblies of amphiphilic block copolymer obtained from grape seed vegetable oil derivatives (sustainable renewable resources) as well as their tunability are of great interest for biomass valorization at the nanoscale level.

\section{Introduction:}

Combining polymers having different properties allows to obtain interesting architectures ${ }^{[1]}$ such as linear block copolymers, star-shape copolymers, graft copolymers or dendrimers. ${ }^{[2,3]}$ Amphiphilic diblock copolymers are especially interesting for their self-assembling properties in liquid medium and their ability to produce soft objects ${ }^{[4,5]}$ such as micelles, vesicles ${ }^{[6]}$ or polymersomes. ${ }^{[7]}$ The size of these soft objects ranges from few nanometers to hundred micrometers $^{[8]}$ and the resulting self-organization properties are used in a wide range of applications such as emulsifiers ${ }^{[9]}$ and stabilizers for food or cosmetics. Other important application fields are nanotechnologies ${ }^{[10]}$ and drug delivery since the self-assembling of copolymers allows the formation of nanoreactors and the encapsulation of active molecules 
such as drugs. ${ }^{[11,12]}$ So far, diblock copolymers were mainly obtained from petroleumorigin but the rarefaction of fossil resources is now favoring research focusing on the development and the characterization of fully or partially bio-based copolymers. Many investigations concern now the synthesis of non-ionic copolymers and the study of their physico-chemical properties. More recently, fully bio-sourced copolymers have been reported such as alkyl polyglycosides, ${ }^{[13]}$ glycolipids, ${ }^{[14]}$ lipids linked to polyglycerol, ${ }^{[15]}$ glycoproteins forming vesicles, ${ }^{[16]}$ oligosaccharides linked to hydrophobized oligosaccharides forming micelles ${ }^{[17]}$ or nucleolipids leading to various supramolecular assemblies. ${ }^{[18]}$ Partially bio-sourced copolymers can be divided into two main categories: copolymers based on sugar derivatives or based on lipids. Within the first family, various glycopolymers associating responsive poly $\left(N\right.$-isopropylacrylamide) and oligosaccharides such as linear maltoheptaose, ${ }^{[19]}$ branched xyloglucooligosaccharide ${ }^{[20]}$ or cyclic $\beta$-cyclodextrin ${ }^{[21]}$ were synthesized and their ability to form nanoparticles or vesicles was also investigated. Glycopolymers linked to a polystyrene block were reported to self-organize into films with inter-domain spacing of about $10 \mathrm{~nm}$ which underwent transition phase in presence of bipyridine. ${ }^{[22]}$ Specific glycopolymers containing a silicon-based block ${ }^{[23]}$ and fluorescent $\pi$-conjugated poly(3-hexylthiophene $)^{[24]}$ showed interesting organization behaviors in periodic films made by approximately $5 \mathrm{~nm}$ diameter cylinders (in dry state) and vesicles (in liquid state), respectively. The second category gathers lipopolymers based on vegetable oils or their derivatives and a hydrophilic block such as polyacrylamide, ${ }^{[25]}$ poly(ethylene oxide) (PEO) or peculiar polyoxazolines such as poly(2-methyl-2-oxazoline), poly(2-ethyl-2-oxazoline) or poly(2-(2- $N$-pyrrolidonylethyl)2-oxazoline). ${ }^{[26]}$ The most reported lipopolymer is based on PEO since it is easily available and its physical properties in solution are well-known. For instance, lipid mono-and di-end capped PEO molecules were found to self-assemble in micelle and flower-like micelle, respectively. An analysis in the dilute regime showed that the effective interaction radius was close to the hydrodynamic radius. Moreover, a study inthe semi-dilute regime indicated that micelles were organized in a liquid-like ordered structure, ${ }^{[27]}$ and recent investigations proved that they were good emulsifiers especially for high internal phase emulsions. ${ }^{[9,28]}$ More complex structures such as PEO-phosphatidyl ethanolamine were investigated for drug delivery systems because they had a low critical micelle concentration (CMC) (about $10^{-6} \mathrm{~mol}$ $\mathrm{L}^{-1}$ ), a good drug loading with an efficiency varying between 1.5 and $50 \%$ of introduced molecules and a high retention (over 75\%). ${ }^{[3,29]}$ One may also add that lipopolymers based on polyoxazoline, especially on poly(2-methyl-2-oxazoline) (POx), were found to have similar behavior as PEO-based ones in terms of self-organization and biomedical 
requirements. ${ }^{[26,30]}$ Furthermore, poly(2-methyl-2-oxazoline) has been proved to be non-toxic whereas recent studies highlighted the bioaccumulation of PEO chains into human organisms. ${ }^{[31,32]}$ Only few lipopolymers based on lipidic chain and poly(2-methyl-2oxazoline), so-called LipoPOx, have been synthesized and reported in the literature (Figure 1).On one hand, dialkyl-lipopolymers based on 1,2-O-dioctadecyl-sn-glycerol (Figure 1b), ${ }^{[33]}$ disteaorylphosphatidylethanolamine (Figure 1c) ${ }^{[34]}$ and 1,2-didodecanoylpropyl (Figure 1d) ${ }^{[31]}$ were developed. So far, they have been studied in air-water interface as mono-layer ${ }^{[35-39]}$ or supported membranes ${ }^{[40,41]}$ but never in solution. On other hand, lipid mono- and di-end capped POx molecules, leading thus to linear $\mathrm{AB}$ (Figure 1a) ${ }^{[42]}$ and $\mathrm{BAB}^{[43]}$ structures, were studied in solution as reported by Volet et al. ${ }^{[42,43]}$ Nano-hairy micelles were observed and the influence of the lipophilic and hydrophilic parts on theradius of gyrationwas studied by smallangle neutron scattering in deuterated dichloromethane and water. ${ }^{[44]}$ Fluorimetry and viscosimetry analyses were also performed and the effect of adding cyclodextrin in order to reduce hydrogen bonding was detailed. ${ }^{[42]}$ Recently, we have developed LipoPOx based on castor oil by modifying natural hydroxylated groups with tosylate groups to obtain macroinitiator for the polymerization of 2-methyl-2-oxazoline (Figure 1e). ${ }^{[45]}$ Such lipopolymers were found to form aggregates in solution and star morphologies in solid state. ${ }^{[45]}$ To the best of our knowledge, the self-assembly in water and in organic solvents of complex structures of LipoPOx has never been detailed in the literature.

In the present paper, the behavior in solution of original structures of LipoPOx is investigated. These lipopolymers are based on either fatty esters or triglycerides bearing one poly(2methyl-2-oxazoline) chain grafted on one fatty chain, in the case of the triacylglycerol (Figure If and $1 \mathrm{~g}$, respectively). The synthesis of such structures was described in our previous paper $^{[46]}$ and the present contribution reports the study of the self-assembly of LipoPOx in aqueous medium by dynamic light scattering (DLS) associated with various complementary techniques such as nanoparticle tracking analysis (NTA), atomic force microscopy (AFM) and transmission electron microscopy (TEM). The influence of both lipophilic and hydrophilic parts on the particle size is investigated as well as the behavior of self-assembled mixtures of two different lipopolymers. Finally, the effect of adding an immiscible solvent (water / toluene) on the particle size is highlighted.

\section{$\underline{\text { Experimental section: }}$}


Synthesis: The synthesis of the copolymers based on polyoxazoline and grape seed vegetable oil (GSO) or fatty ester (methyloleate (MO))wasextensively described in our previous joint publication mainly focused on chemistry. ${ }^{[46]}$

Dynamic light scattering (DLS): DLS measurements were performed at CERMAV ${ }^{[47,48]}$ using an apparatus of type ALV/CGS-8F S/N 069 (ALV, Langen, Germany) ${ }^{[49]}$ equipped with a $35 \mathrm{~mW}$ red helium-neon linearly polarized laser operating at a wavelength of $632.8 \mathrm{~nm}$ (JDSU, Milpitas, USA) and an ALV/LSE-5004 multiple $\tau$ digital correlator with a $125 \mathrm{~ns}$ initial sampling time. The aqueous copolymer suspensions were successively filtered through 0.45 and then $0.1 \mu \mathrm{m}$ hydrophilic PTFE syringe filters (Whatman, Maidstone, UK), loaded in $10 \mathrm{~mm}$ diameter cylindrical cells and thermalized at a constant temperature of $25.0 \pm 0.1{ }^{\circ} \mathrm{C}$ prior to measurement. The wave vector modulus $(\mathrm{q})$ is equal to $(4 \pi \mathrm{n} / \lambda) \sin (\theta / 2)$ where $n$ represents the refractive index of the pure solvent (or pure solvent mixture), $\lambda$ is the laser wavelength and $\theta$ designates the scattering angle. Data were collected typically for a counting

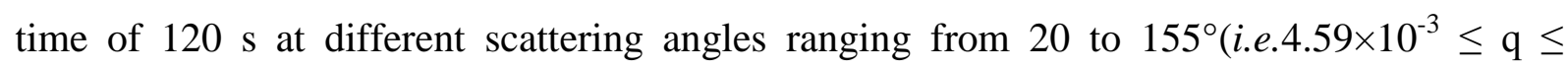
$2.58 \times 10^{-2} \mathrm{~nm}^{-1}$ in pure water)by step of $5^{\circ}$ using the digital ALV correlator control software. The reproducibility of the carried out measurements was checked at least 3 times. The relaxation time distribution was obtained using the CONTIN analysis ${ }^{[50,51]}$ of the autocorrelation function $\left(\mathrm{g}^{(2)}-1\right)$.

Ultraviolet-visible spectrophotometry: The aqueous copolymer suspensions were checked at CERMAV with the help of a Cary 50 Bio ultraviolet-visible spectrophotometer (Varian/Agilent Technologies, Palo Alto, USA) not to absorb light at the helium-neon laser wavelength used in DLS experiments (i.e. $632.8 \mathrm{~nm}$ ), thus avoiding local convection currents. Indeed, at $2 \mathrm{mg} \mathrm{mL}^{-1}$ and $632.8 \mathrm{~nm}$, no local maximum or shoulder is present and the absorbances are typically $5.93 \times 10^{-3}$ after removal of the solvent signal (data not shown).

Atomic force microscopy (AFM): Sample preparation was done as follows: Silica wafers were thoroughly washed with Milli-Q water characterized by a resistivity of $18.2 \mathrm{M} \Omega \mathrm{cm}$, with acetone and then for $2 \mathrm{~h}$ with fuming nitric acid. They were subsequently rinsed with Milli-Q water and acetone. Then, the aqueous copolymer suspensions at $0.04 \mathrm{mg} \mathrm{mL}^{-1}$ were successively filtered through 0.45 and then $0.1 \mu \mathrm{m}$ hydrophilic PTFE syringe filters (Whatman, Maidstone, UK) and $50 \mu \mathrm{L}$ were dropped onto the silica wafers which were allowed to dry for 4 days in an exicator under static vacuum in presence of silica gel. AFM 
imaging was carried out at ICMG at room temperature using a Pico Plus commercial instrument (Molecular Imaging, Phoenix, USA). A $100 \times 100 \mu \mathrm{m}^{2}$ piezoelectric scanner was used and $512 \times 512$ data points were acquired. Images were obtained in tapping mode using silicon tips with a spring constant of $48 \mathrm{~N} \mathrm{~m}^{-1}$ and a resonance frequency of approximately $190 \mathrm{kHz}$ (Vista Probes, Phoenix, USA). Data treatment (i.e. height measurement after baseline correction only) and presentation were realized with the help of the Gwyddion software.

Transmission electron microscopy (TEM): Sample preparation was done as follows: The aqueous copolymer suspensions at $0.04 \mathrm{mg} \mathrm{mL}^{-1}$ were successively filtered through 0.45 and then $0.1 \mu \mathrm{m}$ hydrophilic PTFE syringe filters (Whatman, Maidstone, UK) and $4 \mu \mathrm{L}$ weredropped onto glow discharged carbon coated copper grids. Then, $4 \mu \mathrm{L}$ of a $2 \mathrm{w} / \mathrm{v} \%$ aqueous uranyl acetate negative stain solution was added prior to complete drying. After a few minutes, the excess liquid was blotted with filter paper and the grids were allowed to dry for one day in presence of silica gel. TEM imaging was performed at CERMAV using a CM200 microscope operating at $80 \mathrm{kV}$ (Philips/FEI, Hillsboro, USA). Images were recorded on SO163 films (Kodak, Rochester, USA) and the nanoparticle mean diameters were determined with the Scandium software.

Nanoparticle tracking analysis (NTA): NTA was carried out at CERMAV using a LM10HSoptical microscope setup equipped with a camera and a chamber mounted on the modified microscope stage (Nanosight, Amesbury, UK). The original aqueous copolymer suspension at $2 \mathrm{mg} \mathrm{mL}^{-1}$ was diluted with Milli-Q water down to $0.08 \mathrm{mg} \mathrm{mL}^{-1}$ and introduced into the chamber by a syringe. A video clip of the nanoparticles submitted to their natural Brownian motion was captured over $30 \mathrm{~s}$ at $25.0^{\circ} \mathrm{C}$ and analyzed by the analytical software version 2.1 .

\section{$\underline{\text { Results and Discussion: }}$}

\section{LipoPOx copolymer self-assembly in water ${ }^{[52]}$ / Effect of the lipophilic block length:}

The synthesis of the copolymers based on polyoxazoline and grape seed vegetable oil or fatty ester (LipoPOx) was reported elsewhere. ${ }^{[46]} \mathrm{L}-\mathrm{C}_{18}-\mathrm{POx}_{\mathrm{n}}$ designates a linear structure made with an alkyl chain (Figure 1a) where $\mathrm{n}$ is the oxazoline monomer unit number (n), T-MO$\mathrm{POx}_{\mathrm{n}}$ represents a T-structure made with a fatty ester especially methyloleate (MO) (Figure 1f) 
and Tri-GSO-POx $\mathrm{x}_{\mathrm{n}}$ designates a trident-structure made with a triglyceride of grape seedvegetable oil(GSO) (Figure 1g). When LipoPOx are mixed with water, ${ }^{[52]}$ they spontaneously self-assemble as deduced from the dynamic light scattering (DLS) experiments (Figure 2) carried out in a wide range of scattering angles. Indeed, the relaxation time distributions obtained from the autocorrelation functions $\left(\mathrm{g}^{(2)}-1\right)$ and showed at a scattering angle of 40,90 and $140^{\circ}$ for T-MO-POx 25 and Tri-GSO-POx 23 exhibit a monomodal and narrow exponential decay (Figure $2 \mathrm{a}$ and $2 \mathrm{~b}$ ). From the $\mathrm{x}$-positions of the relaxation time distribution maxima $(1 / \Gamma)$, the proportional dependence of the $\Gamma$-values (i.e.the relaxation frequencies) on the square of the wave vector modulus $\left(\mathrm{q}^{2}\right)$ (Figure $2 \mathrm{c}$ and $2 \mathrm{~d}$ ) is attributed to the Brownian diffusive motion of particles. ${ }^{[53,54]}$ Indeed, internal modes such as the Rouse or Zimm modes are preferentially probed in conditions such as $\mathrm{qD}_{\mathrm{G}}>4^{[53,55,56]}$ what is presently not at all fulfilled $\left(\mathrm{D}_{\mathrm{G}}\right.$ designates the mean-square diameter of gyration and is in the same order of magnitude as the hereafter given $\mathrm{D}_{\mathrm{h}}$-values). Moreover, transient uncontrolled aggregates are not observed. The slope of $\Gamma=\mathrm{f}\left(\mathrm{q}^{2}\right)$ dependence is equal to the diffusion coefficient (D) of the particles from which the hydrodynamic diameter $\left(D_{h}\right)^{[57]}$ of the particles is calculated for each sample using the well-known Stokes-Einstein equation. ${ }^{[58,59]}$ The so-calculated $\mathrm{D}_{\mathrm{h}^{-}}$ values are 10.1 and $19.2 \mathrm{~nm}$ for T-MO-POx 25 and Tri-GSO-POx 23 , respectively (Figure 2c and 2d). These two LipoPOx copolymersystems differ only by their lipophilic blocks, and particularly their lengths $\left(\mathrm{C}_{19}\right.$ for the fatty ester-based T-MO-POx 25 and $\mathrm{C}_{57}$ for the triglyceride-based Tri-GSO-POx ${ }_{23}$ ). Thus, a higher aggregation number needs to be reached in the case of Tri-GSO-POx 23 to have an efficient stabilization by the hydrophilic block (i.e. polyoxazoline), driving the self-organization in aqueous medium towards a much bigger characteristic size.Similar experimentaland modeling tendency as a function of the lipophilic block length was observed for other amphiphilic block copolymers such as poly(styrene- $b-4-$ vinylpyridine). ${ }^{[60]}$ Furthermore, Volet et al. ${ }^{[43,44]}$ reported that, for a moderate change in the lipophilic block length (i.e. by $50 \%$, from $\mathrm{C}_{12}$ to $\mathrm{C}_{18}$ ), the characteristic size in dichloromethane remains constant whatever for similar linear diblock ${ }^{[44]}$ or similar linear triblock lipophilic/hydrophilic/lipophilic systems. ${ }^{[43]}$ The evolution of the lipophilic block length is, for the present systems, much more drastic (i.e. by $200 \%$, from $\mathrm{C}_{19}$ to $\mathrm{C}_{57}$ ).

Experimentally, the critical micelle concentration (CMC) is found to be equal to $0.01-0.02$ $\mathrm{mg} \mathrm{mL} \mathrm{m}^{-1}$ as determined by fluorescence and DLS experiments for Tri-GSO-POx 23 in water (data not shown). The CMC-values published by Volet et al. ${ }^{[42]}$ and determined by fluorescence measurements in water were in the same order of magnitude. Thus, the 
copolymer concentrations used in the present contribution (from 0.04 to $4 \mathrm{mg} \mathrm{mL}^{-1}$ ) are higher than our CMC-value, guaranteeing the self-assembling.

\section{Effect of the lipophilic block structure on the LipoPOx copolymer self-assembly in water:}

So as to better apprehend the influence of the lipophilic block structure on the self-assembly, the $\mathrm{D}_{\mathrm{h}}$-values are measured by DLS for $\mathrm{L}-\mathrm{C}_{18}-\mathrm{POx}_{26}$ (having a linear shape) and T-MO-POx 25 (having a T-shape) copolymer suspensions (Figure 3). The lipophilic block molecular weight is almost the same for both compounds (254 versus $297 \mathrm{~g} \mathrm{~mol}^{-1}$ ), their architectures only differ from one to another. The $\mathrm{D}_{\mathrm{h}}$-value decreases by $16 \%$ from the linear to the $\mathrm{T}$-shape. This result confirms that a branched polymer has a smaller characteristic size than a linear polymer (all other things being held constant and particularly the molecular weight). ${ }^{[61,62]}$ This behavior was already reported for polystyrene ${ }^{[63]}$ and even for polyelectrolytes. ${ }^{[64]}$ The contraction is characterized by the so-called shrinking factor defined as the ratio at the power 3 of the $D_{h}$-values of the T-structure to the linear structure. ${ }^{[61,62]}$ It is equal to 0.596 , meaning that the spherical nanoparticle volume is roughly divided by a factor of 2 when modifying the lipophilic block structure.

\section{T-MO-POx ${ }_{n}$ (having a T-shape) copolymer self-assembly in water / Effect of the hydrophilic block length:}

In order to probe the influence of the hydrophilic block length on the self-assembly, the $\mathrm{D}_{\mathrm{h}^{-}}$ values are measured by DLS for T-MO-POx ${ }_{n}$ copolymer suspensions from $n=0$ to 55 (Figure 4). The error bars relatively to the LipoPOx copolymers are small (typically $4 \%$ in relative value), indicating a satisfying reproducibility of the measurements. For $n=0$, the compound corresponds simply to hydroxylated methyloleate (i.e. methyloleate functionalized with 2mercaptoethanol). ${ }^{[46]}$ Its lipophilic character is not counter-balanced by numerous hydrophilic functional groups (only one alcohol function and one ester function per $374 \mathrm{~g} \mathrm{~mol}^{-1}$ molecule), thus leading to a large characteristic size of $314 \mathrm{~nm}$ and a high relative standard deviation of 8 $\%$ (versus typically 30 times less and $4 \%$ for the three compounds whose n-value differs from $0)$. With increasing n-values, the $\mathrm{D}_{\mathrm{h}}$-values increase linearly but moderately (Figure 4). The characteristic size increases by $73 \%$ when $n$ increases by $323 \%$. It means that the first order size effect comes from the lipophilic block (as discussed in paragraph 1) whereas the characteristic size can be tuned more finely (i.e. in a second order) by choosing appropriately the hydrophilic block length. Such a linear behavior was reported on similar linear triblock 
alkane/POx/alkane systems. ${ }^{[43]}$ Furthermore, the stability of the copolymer suspensions, particularly for T-MO-POx 13 at $2 \mathrm{mg} \mathrm{mL}^{-1}$ in water, is successfully checked using DLS over an aging time of 30 days in terms of $D_{h}$-value $(8.7 \pm 0.2$ versus $8.6 \pm 0.2 \mathrm{~nm}$ at short times, Figure 4), relaxation time distribution and scattering intensity (data not shown): No sedimentation, no coalescence or uncontrolled aggregation are observed. The experimentally obtained $\mathrm{D}_{\mathrm{h}}$-values (typically $10 \mathrm{~nm}$ ) are too small to envisage static light scattering measurements aiming at getting information on the molar mass or the nanoparticle morphology such as the form factor. For this reason, microscopic techniques are used hereafter.

Atomic force microscopy (AFM) and transmission electron microscopy (TEM) imaging are performed on $\mathrm{T}-\mathrm{MO}-\mathrm{POx}_{25}$ (Figure 5a and 5c).Well-defined spherical nanoparticles are observed on the substrates. They are individual and no sign of coalescence upon drying is observed. Statistic treatment of the images carried out on few hundred nanoparticles gives by AFM measurements the average height $\mathrm{H}_{\mathrm{AFM}}, \mathrm{MAX}=7.7 \mathrm{~nm}$ and by TEM measurements the average diameter $\mathrm{D}_{\text {TEM, MAX }}=8.9 \mathrm{~nm}$ (Figure $5 \mathrm{~b}$ and $5 \mathrm{~d}$ ). Both values are within experimental error in very good agreement, and as expected slightly smaller than the value $D_{h}=10.2 \mathrm{~nm}$ obtained in the swollen state by DLS (Figure 4).

\section{Tri-GSO-POx $\mathrm{x}_{\mathrm{n}}$ (having a trident-shape) copolymer self-assembly in water / Effect of the hydrophilic block length:}

The $\mathrm{D}_{\mathrm{h}}$-values are measured by DLS for Tri-GSO-POx $\mathrm{x}_{\mathrm{n}}$ copolymer suspensions from $\mathrm{n}=0$ up to 56 (Figure 6a). The obtained profile is quite comparable with the one measured for the Tshape compounds (Figure 4). However, for any given $n$-value, the $D_{h}$-values are higher (typically 2 times bigger, except for $\mathrm{n}=0$ ) for Tri-GSO-POx $\mathrm{n}$ due to their longer lipophilic blocks and thus stronger lipophilic character in aqueous medium.

In order to complete the DLS results indicating the presence of nano-objects, nanoparticle tracking analysis (NTA)is carried out onTri-GSO-POx ${ }_{56}$ at $0.08 \mathrm{mg} \mathrm{mL}^{-1}$ in water (Figure $6 \mathrm{~b}$ ). The values $n=11$ and 23 cannot be probed since the expected characteristic sizes are at the low resolution limit (i.e. about $20-30 \mathrm{~nm}$ for organic systems due to their moderate nanoparticle refractive indexes compared to inorganic systems). ${ }^{[65-67]}$ The nanoparticles are illuminated by a laser and tracked individually in a video clip filmed with a charge-coupled device (CCD) camera. Those that just undergo natural Brownian motion ${ }^{[68]}$ in their liquid medium are taken in account by the software, their diffusion coefficients are individually estimated from which their hydrodynamic diameters $\left(\mathrm{D}_{\mathrm{h}, \mathrm{NTA}}\right)$ are calculated using the Stokes- 
Einstein equation. ${ }^{[58,59]}$ The hydrodynamic diameter distribution is narrow and gives the average diameter $D_{h}$, NTA, MAX $=24.0 \mathrm{~nm}$ (Figure $6 \mathrm{c}$ ). This value is notably smaller than $D_{h}=$ $30.3 \mathrm{~nm}$ obtained by DLS (Figure 6a). This shift is reasonably attributed to the fact that NTA gives by nature access to number weighted hydrodynamic diameter distributions whereas DLS consists of mass weighted distributions. ${ }^{[69,70]}$ No shift is thus observed for strictly speaking monodisperse samples(what is presently not the case). Both characterization methods are complementary and in very good agreement.

AFM and TEM imaging are performed on Tri-GSO-POx ${ }_{11}$, showing dry spherical nanoparticles (Figure $7 \mathrm{a}$ and $7 \mathrm{c}$ ). As for T-MO-POx 25 , no drastic coalescence or aggregation of nanoparticles is observed. The average height $\mathrm{H}_{\mathrm{AFM}, \mathrm{MAX}}=5.5 \mathrm{~nm}$ and the average diameter $\mathrm{D}_{\text {TEM, MAX }}=11.1 \mathrm{~nm}$ are obtained by the statistic treatment of the AFM and TEM images, respectively (Figure $7 b$ and $7 d$ ). This difference lies on different affinities of the nanoparticles with the substrates (silica wafer and glow discharged carbon coated copper grid, respectively) combined with weaker mechanical resistance in the unswollen state of the nanoparticles based on Tri-GSO-POx ${ }_{11}$ compared to the ones based on T-MO-POx 25 (they spread a bit, mainly on the silica wafer). Indeed, these two values differ by a factor of 4 and 2, respectively, from the value $D_{h}=20.4 \mathrm{~nm}$ obtained by DLS (Figure 6a). Thus, the drying step affects more strongly the nanoparticles based on Tri-GSO-POx ${ }_{11}$ in terms ofcharacteristic size, but not in terms of morphology.

\section{Effect of the concentration on the LipoPOx copolymer self-assembly in water:}

Todetermine the possible influence of the copolymer concentration on the self-assembly, the $\mathrm{D}_{\mathrm{h}}$-values are measured by DLS for T-MO-POx 55 (having a T-shape) and Tri-GSO-POx 56 (having a trident-shape) copolymer suspensions (Figure 8). In the studied concentration range going from 1 to $4 \mathrm{mg} \mathrm{mL}^{-1}$ (i.e. for concentrations above the typical CMC-value discussed in paragraph 1), the $\mathrm{D}_{\mathrm{h}}$-values remain constant at about 15.0 and $32.0 \mathrm{~nm}$, respectively.

In order to go further on the interpretation of the results, and knowing that polyoxazoline is a semi-rigid molecule with a persistence length $l_{P}=2.0 \mathrm{~nm},{ }^{[44]}$ we propose to have a close look at the morphology of the self-assembled LipoPOx copolymer structure: micelle or other structure? The notion of persistence length is strongly correlated to worm-like chain model $^{[71,72]}$ valid for semi-flexible polymers in dilute solution and could be used to appreciate, in a first approximation, the mean-square diameter of gyration $\left(D_{G}\right)$ :

$$
D_{G}^{2}=\frac{4 l_{P} L_{C}}{3}-4 l_{P}^{2}+\frac{8 l_{P}^{3}}{L_{C}}-\frac{8 l_{P}^{4}}{L_{C}^{2}}\left[1-\exp \left(-\frac{L_{C}}{l_{P}}\right)\right]
$$


(Equation 1) ${ }^{[71,72]}$

Where $\mathrm{L}_{\mathrm{C}}$ designates the contour length. The trident-shape compound having quite a complex structure which cannot be rendered by the simplicity of the chosen equation, we should at that point focus on the T-shape compound (T-MO-POx $\left.{ }_{55}\right)$. For $\mathrm{n}=55$, making the hypothesis that the lipophilic block behaves as the semi-flexible hydrophilic block (therefore $\mathrm{n}_{\text {FICTITIOUS }}=$ $55+(18 / 3)=61)$, we get $\mathrm{L}_{\mathrm{C}}=27.3 \mathrm{~nm}$ and $\mathrm{D}_{\mathrm{G}}=7.7 \mathrm{~nm} .{ }^{[73]}$ The result concerning the nanoparticles with a $\mathrm{D}_{\mathrm{h}}$-value at about $15.0 \mathrm{~nm}$, as experimentally measured by DLS (Figure 8):

- is not at all compatible with the simple star-like micelle model ${ }^{[74]}$ for which the characteristic expected diameter would be roughly $2 \mathrm{~L}_{\mathrm{C}}=54.7 \mathrm{~nm}$.

- ishowever compatible with the worm-like chain model ${ }^{[71,72]}$ valid for semi-flexible polymers. More precisely, instead of having a unique copolymer chain leading to a characteristic diameter of $7.7 \mathrm{~nm}$, few of them (less than 10) are self-organized and constitute the nanoparticle so as to get $15.0 \mathrm{~nm}$. This experimental higher latter value may also be due to the hygroscopic character of polyoxazoline ${ }^{[75,76]}$ which contains numerous bound water molecules, increasing its excluded volume and thus the nanoparticle characteristic size.

For these reasons, in the present case, the terminology "micelle" may be ambiguous. That is why "self-assembly" or simply "nanoparticle" should be preferred. From experimental results obtained from different amphiphilic block copolymers with molecular weights between 2,700 and 20,000 $\mathrm{g} \mathrm{mol}^{-1}$, Discher et al. ${ }^{[4,6]}$ gave a simple unifying rule for the formation of selfassemblies in water. For this purpose, they introduced the hydrophilic ratio $\left(f_{\text {HYDRO }}\right)$, defined as the ratio of the hydrophilic part to the total mass, which is equal in our case to 94 and $85 \%$ for T-MO-POx ${ }_{55}$ (with a molecular weight of about 5,190 $\left.\mathrm{g} \mathrm{mol}^{-1}\right)^{[77]}$ and Tri-GSO-POx 56 (with a molecular weight of about 5,840 $\mathrm{g} \mathrm{mol}^{-1}$ ), ${ }^{[77]}$ respectively. Both values are notably higher than the minimum required value $\mathrm{f}_{\text {HYDRO }}=45 \%{ }^{[4,6]}$ from which direct structures (which cannot be vesicles) are expected to form in water.

\section{Mixtures of LipoPOx copolymers / Mixtures of solvents:}

When mixing together the T-MO-POx 25 and Tri-GSO-POx 56 powders in the weight ratios 90/10 and 98/2 w/w\% before adding water, the relaxation time distributions obtained from the autocorrelation functions measured by DLS at a scattering angle of $90^{\circ}$ show for both systems a bimodal exponential decay (Figure 9a). The calculated $\mathrm{D}_{\mathrm{h}}$-values reach roughly 10.0 and $50.0 \mathrm{~nm}$, almost independently on the feed ratio (Figure 9b). These two values differ by a 
factor of 5 , much more than the factorof 3 mentioned by Trushkevychet al. ${ }^{[65]}$ andconsidered as the low resolution limit from which two size distributions of nanoparticles can be unambiguously distinguished by DLS.The fact that the two peaks appearing in the relaxation time distributions have more or less the same surfacearea (Figure 9a, in the case of the feed ratio 90/10) does not mean that an equal number of small and big nanoparticles are present. Indeed, DLS experiment data processing with the CONTIN analysis leads to mass weighted hydrodynamic diameter distributions: Bigger nanoparticles contribute much stronger. ${ }^{[69,70]}$ Thus, to convert simply such mass weighted distributions into number weighted distributions $^{[59]}$ - what may be more pragmatic to the physico-chemist - the hypotheses are that hard sphere-like nanoparticles are present and that the small (characterized by an hydrodynamic diameter $\mathrm{D}_{\mathrm{h}}$, SMALL) and big (characterized by an hydrodynamic diameter $\mathrm{D}_{\mathrm{h}}$, BIG) nanoparticles have the same density. In that case, we have:

$$
\frac{N_{S M A L L}}{N_{B I G}}=\left(\frac{D_{h, B I G}}{D_{h, S M A L L}}\right)^{3}\left(\frac{A_{S M A L L}}{1-A_{S M A L L}}\right)
$$

(Equation 2) $^{[59]}$

Where $\mathrm{N}_{\text {SMALL }}$ designates the number of small nanoparticles, $\mathrm{N}_{\mathrm{BIG}}$ is the number of big nanoparticles and $A_{S M A L L}$ represents in the relaxation time distribution the percentage of the total surface area corresponding to the surface area under the peak related to the small nanoparticles. In the present example (Figure 9a), we have $\mathrm{D}_{\mathrm{h}, \mathrm{SMALL}}=10.8 \mathrm{~nm}, \mathrm{D}_{\mathrm{h}, \mathrm{BIG}}=54.0$ $\mathrm{nm}$ and $\mathrm{A}_{\mathrm{SMALL}}=34 \%$. Thus, we get $\mathrm{N}_{\mathrm{SMALL}}=64.4 \mathrm{~N}_{\mathrm{BIG}}$. Therefore, small nanoparticles are the majority, making up $98 \%$ of the nanoparticles in number. Regarding the assignment of the two here above discussed peaks, when comparing with Figures 4 and 6a, the peak related to the small nanoparticles can be reasonably attributed to the pure T-MO-POx 25 copolymer whereas the peak related to the big nanoparticles may consist of the Tri-GSO-POx 56 copolymer whose outer part is filled and rendered more compact and larger by the much mobile and a bit much hydrophilic T-MO-POx 25 copolymer.

Is it relevant to think that small lipophilicmolecules can easily enter in the lipophilicinner part of the nanoparticles in aqueous medium (or the opposite using small hydrophilic molecules in organic medium)? For this purpose, Tri-GSO-POx 56 at 1 and $2 \mathrm{mg} \mathrm{mL}^{-1}$ in toluene (Figure 10a) and water (Figure 10b), respectively, are subsequently mixed and sonicated with their associated immiscible solvent (water and toluene, respectively). We get stable suspensions whose relaxation time distributions obtained by DLS at a scattering angle of $90^{\circ}$ show systematically a bimodal exponential decay. The $\mathrm{D}_{\mathrm{h}}$-values are roughly 36.0 and220nm (Figure 10). When comparing with Figure 6a, the small-scale objects are assigned to 
nanoparticles based on Tri-GSO-POx 56 slightly swollen by water (or toluene). The shift towards bigger sizes can be reasonably attributed to little variations in the solute viscosity and refractive index when adding the non-miscible compound. These variations are not easy to estimate due to the fact that part of the non-miscible compound may be effectively encapsulated. The large-scale objects can result in droplets of the immiscible solvent stabilized by the Tri-GSO-POx 56 copolymer. The error bars are large, particularly in the case of toluene into water (leading to direct oil-into-water suspensions) (typically $46 \%$ in relative value), suggesting that the stabilization is not so effective. Before the addition of the immiscible solvent, the $\mathrm{D}_{\mathrm{h}}$-values are higher in water compared to toluene, they differ by 16 $\%$. This behavior is due to the hydrophilic and even hygroscopic character of polyoxazoline $^{[75,76]}$ and also to the fact that the Tri-GSO-POx 56 compound is highly unsymmetric in terms of steric hindrance of the lipophilic and hydrophilic blocks (Figure 1). Thus, the spatial organizations of the direct and inverted nanoparticles are not equivalent.

\section{Conclusion:}

Original and amphiphilic partially natural copolymers based on polyoxazoline and grape seed vegetable oil derivatives were synthesized with linear, T- and trident-structure. All these structures are found to spontaneously self-organize in water in monomodal, narrow and stable colloidal suspensions as shown using DLS experiments. Globaly, the obtained $D_{h}$-values are at the nanometer-scale and range from 8.6 to $32.5 \mathrm{~nm}$. Specifically, the nanoparticle characteristic size increases strongly with increasing natural block (i.e. lipophilic block) length, from $10.1 \mathrm{~nm}$ (for $\mathrm{C}_{19}$ ) to $19.2 \mathrm{~nm}$ (for $\mathrm{C}_{57}$ ) due to higher hydrophobic interactions (all other things being held constant). Furthermore, $D_{h}$-values slightly increase with the polyoxazoline (i.e. hydrophilic block) length, for both T-and trident-shape. Therefore, the first order size effect comes from the natural block whereas the characteristic size can be tuned more finely (i.e. in a second order) by choosing appropriately the polyoxazoline length. The results of the characteristic sizes obtained by DLS on the copolymer suspensions are in very good agreement withNTAexperiments as well as AFM and TEM imaging techniques where well-definedspherical and individual nanoparticles exhibit a remarkable mechanical resistance upon drying. Moreover, changing the lipophilic block architecture from a linear to a T-shape generates a branching and thus a shrinking by a factor of 2 of the nanoparticle volume, as shown by DLS on the copolymer suspensions. The presently described use of grape seed vegetable oil derivativesaslipophilic block(or natural sugar derivatives as 
hydrophilic block as found elsewhere), ${ }^{[20,24,78]}$ sustainable renewable resources, and the demonstrated tunability of their self-assembling physico-chemicalproperties are of great interest for biomass valorization at the nanoscale level.

\section{Acknowledgements:}

This research project has been supported by the French centre national de la recherche scientifique (CNRS). The authors are grateful to Ms. Amandine Durand-Terrasson for transmission electron microscopy (TEM) imaging at CERMAV and fruitful discussions.

\section{References and Notes:}

[1] G. Riess, Progress in Polymer Science, 2003, 28, 1107-1170.

[2] P. Alexandridis, Current Opinion in Colloid and Interface Science, 1996, 1, 490-501.

[3] L. Y. Qiu, Y. H. Bae, Pharmaceutical Research, 2006, 23, 1-30.

[4] J. Rodríguez-Hernández, F. Chécot, Y. Gnanou, S. Lecommandoux, Progress in Polymer Science, 2005, 30, 691-724.

[5] O. Ikkala, G. ten Brinke, Chemical Communications, 2004, 19, 2131-2137.

[6] D. E. Discher, A. Eisenberg, Science, 2002, 297, 967-973.

[7] B. M. Discher, Y.-Y. Won, D. S. Ege, J. C.-M. Lee, F. S. Bates, D. E. Discher, D. A. Hammer, Science, 1999, 284, 1143-1146.

[8] K. Letchford, H. Burt, European Journal of Pharmaceutics and Biopharmaceutics, 2007, 65, 259-269.

[9] H. Lim, A. Kassim, N. Huang, M. A. Yarmo, Journal of Surfactants and Detergents, 2009, $12,355-362$.

[10] I. W. Hamley, Angewandte Chemie International Edition, 2003, 42, 1692-1712.

[11] M. L. Adams, A. Lavasanifar, G. S. Kwon, Journal of Pharmaceutical Sciences, 2003, 92, 1343-1355.

[12] A. Blanazs, S. P. Armes, A. J. Ryan, Macromolecular Rapid Communications, 2009, 30, 267-277.

[13] W. von Rybinski, K. Hill, Angewandte Chemie International Edition, 1998, 37, 13281345 .

[14] P. K. Vemula, G. John, Accounts of Chemical Research, 2008, 41, 769-782. 
[15] I. Johansson, M. Kjellin, Surfactants from Renewable Resources, Wiley (Chichester, UK), 2010.

[16] C. Schatz, S. Louguet, J.-F. Le Meins, S. Lecommandoux, Angewandte Chemie International Edition, 2009, 48, 2572-2575.

[17] S. de Medeiros Modolon, I. Otsuka, S. Fort, E. Minatti, R. Borsali, S. Halila, Biomacromolecules, 2012, 13, 1129-1135.

[18] A. Gissot, M. Camplo, M. W. Grinstaff, P. Barthélémy, Organic and Biomolecular Chemistry, 2008, 6, 1324-1333.

[19] I. Otsuka, K. Fuchise, S. Halila, S. Fort, K. Aissou, I. Pignot-Paintrand, Y. Chen, A. Narumi, T. Kakuchi, R. Borsali, Langmuir, 2010, 26, 2325-2332.

[20] I. Otsuka, C. Travelet, S. Halila, S. Fort, I. Pignot-Paintrand, A. Narumi, R. Borsali, Biomacromolecules, 2012, 13, 1458-1465.

[21] M. R. Mauricio, I. Otsuka, R. Borsali, C. L. Petzhold, T. S. P. Cellet, G. M. de Carvalho, A. F. Rubira, Reactive and Functional Polymers, 2011, 71, 1160-1165.

[22] K. Aissou, I. Otsuka, C. Rochas, S. Fort, S. Halila, R. Borsali, Langmuir, 2011, 27, 4098-4103.

[23] J. D. Cushen, I. Otsuka, C. M. Bates, S. Halila, S. Fort, C. Rochas, J. A. Easley, E. L. Rausch, A. Thio, R. Borsali, C. G. Willson, C. J. Ellison, ACS Nano, 2012, 6, 3424-3433.

[24] K. Aissou, A. Pfaff, C. Giacomelli, C. Travelet, A. H. E. Müller, R. Borsali, Macromolecular Rapid Communications, 2011, 32, 912-916.

[25] P. Théato, R. Zentel, S. Schwarz, Macromolecular Bioscience, 2002, 2, 387-394.

[26] K. Lüdtke, R. Jordan, P. Hommes, O. Nuyken, C. A. Naumann, Macromolecular Bioscience, 2005, 5, 384-393.

[27] E. Beaudoin, O. Borisov, A. Lapp, L. Billon, R. C. Hiorns, J. François, Macromolecules, 2002, 35, 7436-7447.

[28] I. Johansson, M. Svensson, Current Opinion in Colloid and Interface Science, 2001, 6, 178-188.

[29] A. N. Lukyanov, V. P. Torchilin, Advanced Drug Delivery Reviews, 2004, 56, $1273-$ 1289.

[30] M. C. Woodle, C. M. Engbers, S. Zalipsky, Bioconjugate Chemistry, 1994, 5, 493-496.

[31] M. Einzmann, W. H. Binder, Journal of Polymer Science : Part A : Polymer Chemistry, 2001, 39, 2821-2831.

[32] R. Luxenhofer, G. Sahay, A. Schulz, D. Alakhova, T. K. Bronich, R. Jordan, A. V. Kabanov, Journal of Controlled Release, 2011, 153, 73-82. 
[33] R. Jordan, K. Martin, H. J. Räder, K. K. Unger, Macromolecules, 2001, 34, 8858-8865.

[34] N. Adams, U. S. Schubert, Advanced Drug Delivery Reviews, 2007, 59, 1504-1520.

[35] H. Ahrens, T. R. Bækmark, R. Merkel, J. Schmitt, K. Graf, R. Raiteri, C. A. Helm, ChemPhysChem, 2000, 1, 101-106.

[36] T. R. Bækmark, T. Wiesenthal, P. Kuhn, A. Albersdörfer, O. Nuyken, R. Merkel, Langmuir, 1999, 15, 3616-3626.

[37] A. Wurlitzer, E. Politsch, S. Huebner, P. Krüger, M. Weygand, K. Kjaer, P. Hommes, O. Nuyken, G. Cevc, M. Lösche, Macromolecules, 2001, 34, 1334-1342.

[38] T. R. Bækmark, T. Wiesenthal, P. Kuhn, T. M. Bayerl, O. Nuyken, R. Merkel, Langmuir, 1997, 13, 5521-5523.

[39] C. A. Naumann, C. F. Brooks, G. G. Fuller, T. Lehmann, J. Rühe, W. Knoll, P. Kuhn, O. Nuyken, C. W. Frank, Langmuir, 2001, 17, 2801-2806.

[40] O. Purrucker, A. Förtig, R. Jordan, M. Tanaka, ChemPhysChem, 2004, 5, 327-335.

[41] A. Förtig, R. Jordan, K. Graf, G. Schiavon, O. Purrucker, M. Tanaka, Macromolecular Symposia, 2004, 210, 329-338.

[42] G. Volet, V. Chanthavong, V. Wintgens, C. Amiel, Macromolecules, 2005, 38, 51905197.

[43] G. Volet, A.-C. Lasne Deschamps, C. Amiel, Journal of Polymer Science : Part A : Polymer Chemistry, 2010, 48, 2477-2485.

[44] G. Volet, L. Auvray, C. Amiel, Journal of Physical Chemistry B, 2009, 113, 1353613544.

[45] C. Giardi, V. Lapinte, C. Charnay, J.-J. Robin, Reactive and Functional Polymers, 2009, 69, 643-649.

[46] M. Stemmelen, C. Travelet, V. Lapinte, R. Borsali, J.-J. Robin, accepted in Polymer Chemistry, 2013, doi: 10.1039/C2PY20840G.

[47] M. Rinaudo, S. Pérez, Cellulose, 2007, 14, 85-87.

[48] M. Rinaudo, Carbohydrate Polymers, 1988, 9, 159-168.

[49] ALV-Laser Vertriebsgesellschaft mit beschränkter Haftung (http://www.alvgmbh.de).

[50] S. W. Provencher, Die Makromolekulare Chemie, 1979, 180, 201-209.

[51] J. Bodycomb, M. Hara, Macromolecules, 1995, 28, 8190-8197.

[52] The use of other less hydrophilic solvents such as acetonitrile or dimetylformamide is not successful. Indeed, comparatively to water, they definitely promote the formation of remanent uncontrolled aggregates which are not easy to separate (data not shown). 
[53] B. J. Berne, R. Pecora, Dynamic Light Scattering With Applications to Chemistry, Biology and Physics, Wiley (New York, USA), 1976.

[54] J.-C. Daniel, C. Pichot, Les Latex Synthétiques: Elaboration, Propriétés, Applications, Tec et Doc (London, UK), 2006 (in French).

[55] G. Galinsky, W. Burchard, Macromolecules, 1997, 30, 6966-6973.

[56] V. Trappe, J. Bauer, M. Weissmüller, W. Burchard, Macromolecules, 1997, 30, 23652372.

[57] The hydrodynamic diameter extrapolated from the slope of the angular dependency (presently discussed and shown in Figures 2, 3, 4, 6 and 8) should not be confused with the apparent hydrodynamic diameter obtained at a given scattering angle (shown only in Figures 9 and 10).

[58] A. Einstein, Annalen der Physik, 1905, 322, 549-560 (available on the Internet at the following address: http://onlinelibrary.wiley.com/doi/10.1002/andp.19053220806/pdf) (in German).

[59] A. G. Dal Bó, V. Soldi, F. C. Giacomelli, C. Travelet, B. Jean, I. Pignot-Paintrand, R. Borsali, S. Fort, Langmuir, 2012, 28, 1418-1426.

[60] S. Förster, M. Zisenis, E. Wenz, M. Antonietti, Journal of Chemical Physics, 1996, 104, 9956-9970.

[61] K.-F. Arndt, G. Müller, Polymercharakterisierung, Hanser (Munich, Germany), 1996 (in German).

[62] M. Kurata, M. Fukatsu, Journal of Chemical Physics, 1964, 41, 2934-2944.

[63] S. Podzimek, Light Scattering, Size Exclusion Chromatography and Asymmetric Flow Field Flow Fractionation: Powerful Tools for the Characterization of Polymers, Proteins and Nanoparticles, Wiley (Hoboken, USA), 2011.

[64] W. Burchard, M. Frank, E. Michel, Berichte der Bunsen-Gesellschaft Physical Chemistry Chemical Physics, 1996, 100, 807-814.

[65] O. Trushkevych, N. Collings, T. Hasan, V. Scardaci, A. C. Ferrari, T. D. Wilkinson, W. A. Crossland, W. I. Milne, J. Geng, B. F. G. Johnson, S. Macaulay, Journal of Physics D: Applied Physics, 2008, 41, 125106, 1-11.

[66] S. Barcikowski, A. Menéndez-Manjón, B. Chichkov, M. Brikas, G. Račiukaitis, Applied Physics Letters, 2007, 91, 083113 1-3.

[67] Nanosight Operating Manual (available on the Internet at the following address: http://www.me.umn.edu/centers/cdr/reports/NanoSightManual.pdf). 
[68] A. Einstein, Annalen der Physik, 1906, 324, 371-381 (available on the Internet at the following address: http://www.physik.uniaugsburg.de/theo1/hanggi/History/Einstein1906BMII.pdf) (in German).

[69] V. Filipe, A. Hawe, W. Jiskoot, Pharmaceutical Research, 2010, 27, 796-810.

[70] L. Mazzarino, C. Travelet, S. Ortega-Murillo, I. Otsuka, I. Pignot-Paintrand, E. LemosSenna, R. Borsali, Journal of Colloid and Interface Science, 2012, 370, 58-66.

[71] P. Cifra, T. Bleha, Macromolecular Theory and Simulations, 2007, 16, 501-512.

[72] T. Norisuye, Progress in Polymer Science, 1993, 18, 543-584.

[73] Reassuringly, the Gaussian chain model, involving much more flexible chains in $\Theta-$ solvent conditions (i.e. the polymer / polymer and polymer / solvent interactions compensate each other and the excluded volume effect is canceled out), leads to the lower mean-square diameter of gyration $\mathrm{D}_{\mathrm{G}, \text { GAUSSIAN }}=2 \times\left[61 \times(0.448)^{2} / 6\right]^{0.5}=2.9 \mathrm{~nm}$.

[74] P. Ball, Designing the Molecular World: Chemistry at the Frontier, Princeton University Press (Princeton, USA), 1994.

[75] E. F.-J. Rettler, H. M. L. Lambermont-Thijs, J. M. Kranenburg, R. Hoogenboom, M. V. Unger, H. W. Siesler, U. S. Schubert, Journal of Materials Chemistry, 2011, 21, 1733117337.

[76] H. M. L. Thijs, C. R. Becer, C. Guerrero-Sanchez, D. Fournier, R. Hoogenboom, U. S. Schubert, Journal of Materials Chemistry, 2007, 17, 4864-4871.

[77] The molecular weights are determined by size exclusion chromatography calibrated with poly(methyl methacrylate) standards.

[78] I. Otsuka, K. Aissou, S. Ortega-Murillo, C. Travelet, S. Halila, S. Fort, C. Rochas, R. Borsali, Abstracts of Papers of the American Chemical Society, 2010, 240, 148-POLY.

[79] Each measurement being repeated at least 3 times, the error bars were calculated for each experimental data set and their lengths correspond to the individually calculated standard deviation.

\section{Figures:}


Figure 1.Chemical structures of the amphiphilic copolymers based on polyoxazoline and vegetable oil derivatives (LipoPOx): a) $\mathrm{L}_{-} \mathrm{C}_{18}-\mathrm{POx}_{\mathrm{n}}$ (having a linear shape), f) T-MO$\mathrm{POx}_{\mathrm{n}}\left(\right.$ having a T-shape), g) Tri-GSO-POx ${ }_{\mathrm{n}}$ (having a trident-shape), and b), c), d), e) other chemical structures taken from the literature. ${ }^{[31,33,34,45]}$ 

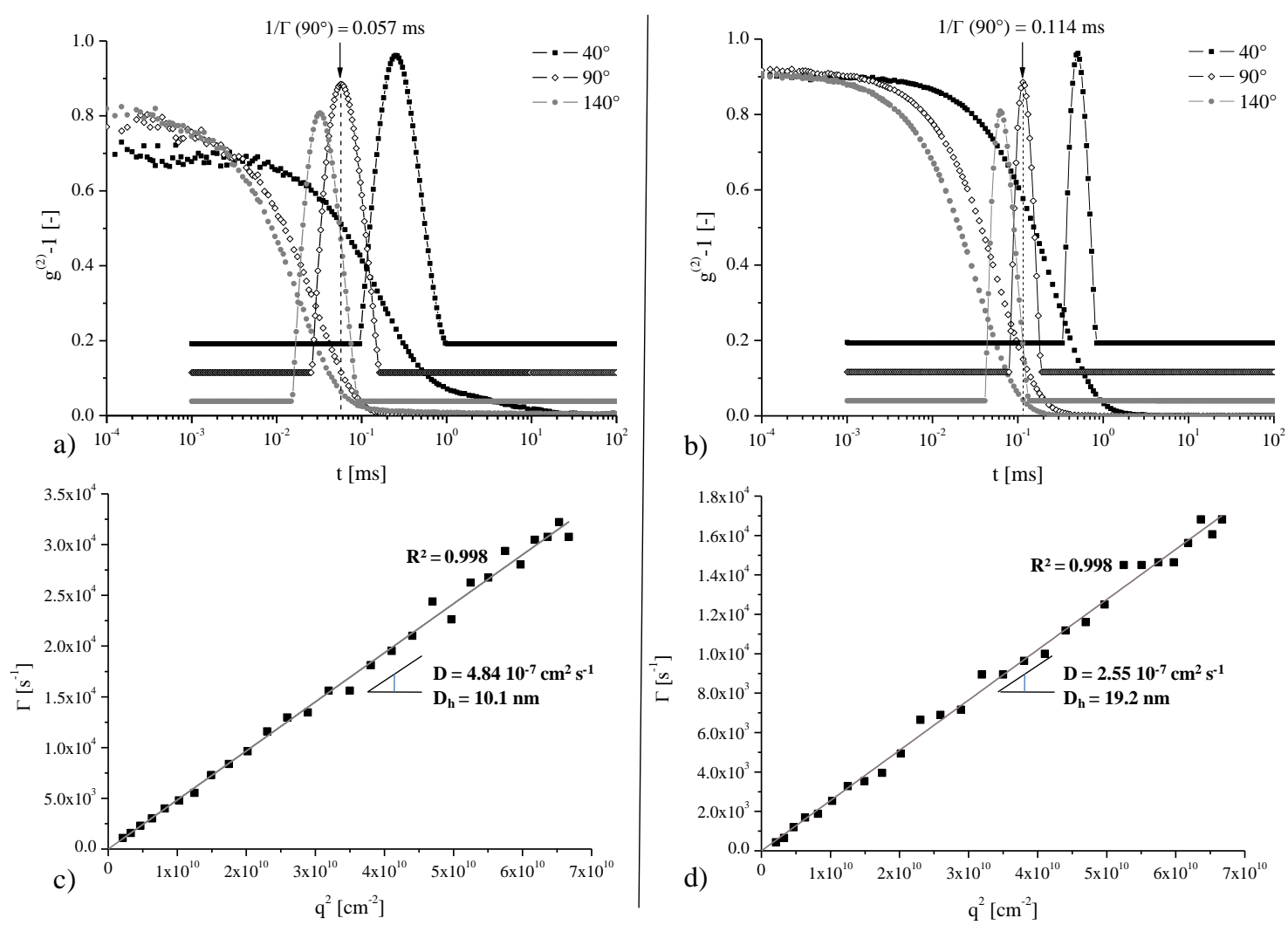

Figure 2. DLS: Autocorrelation function $\left(g^{(2)}-1\right)$ and relaxation time distribution at a scattering angle of 40,90 and $140^{\circ}$ for: a) T-MO-POx ${ }_{25}$, and b) Tri-GSO-POx 23 at $2 \mathrm{mg} \mathrm{mL}^{-1}$ in water. Dependence of the relaxation frequency $(\Gamma)$ on the square of the wave vector modulus $\left(\mathrm{q}^{2}\right)$ between 20 and $155^{\circ}$ by step of $5^{\circ}$ for: c) T-MO-POx 25 , and d) Tri-GSO-POx 23 at $2 \mathrm{mg} \mathrm{mL}^{-1}$ in water (diffusion coefficient (D), hydrodynamic diameter $\left(\mathrm{D}_{\mathrm{h}}\right)$ and correlation coefficient $\left.\left(\mathrm{R}^{2}\right)\right)$. 


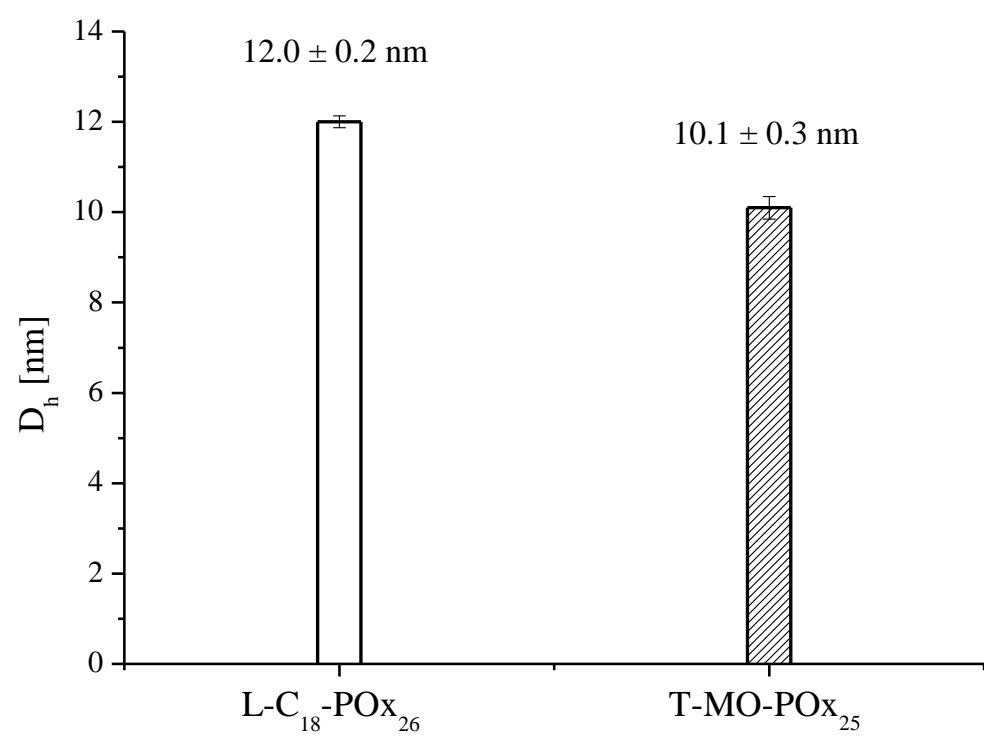

Figure 3. DLS: Hydrodynamic diameter $\left(\mathrm{D}_{\mathrm{h}}\right)$ for a) $\mathrm{L}_{-} \mathrm{C}_{18}-\mathrm{POx}_{26}$, and b) T-MO-POx 25 at 2 $\mathrm{mg} \mathrm{mL}^{-1}$ in water. ${ }^{[79]}$

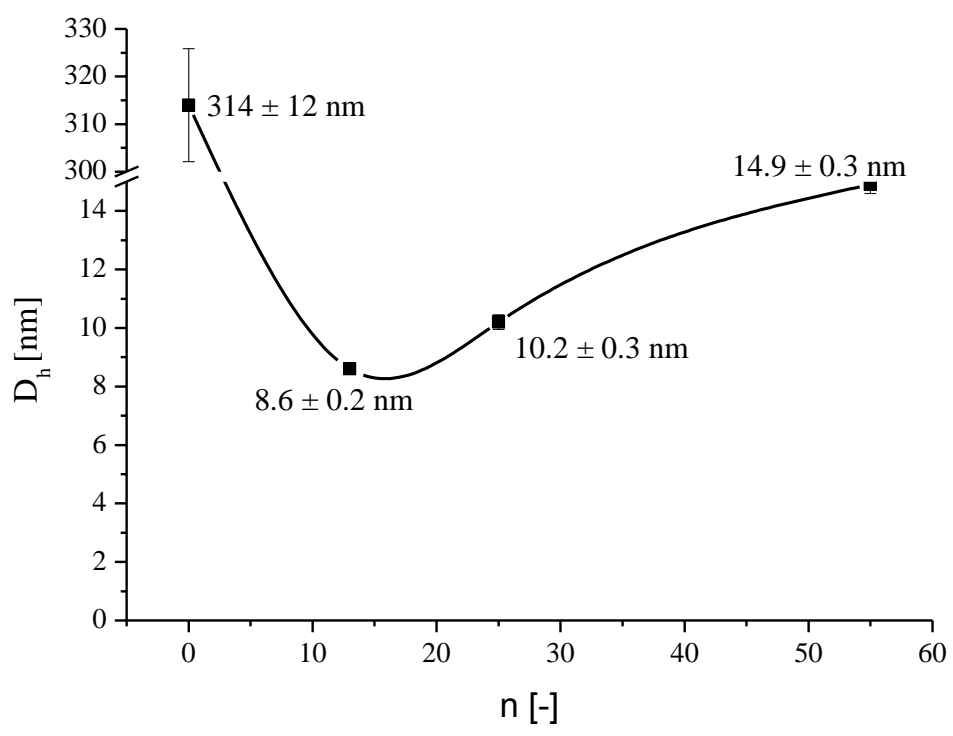

Figure 4. DLS: Dependence of the hydrodynamic diameter $\left(D_{h}\right)$ on the oxazoline monomer unit number (n) for T-MO-POx $\mathrm{n}$ at $2 \mathrm{mg} \mathrm{mL}^{-1}$ in water. ${ }^{\text {[79] }}$ 
a)

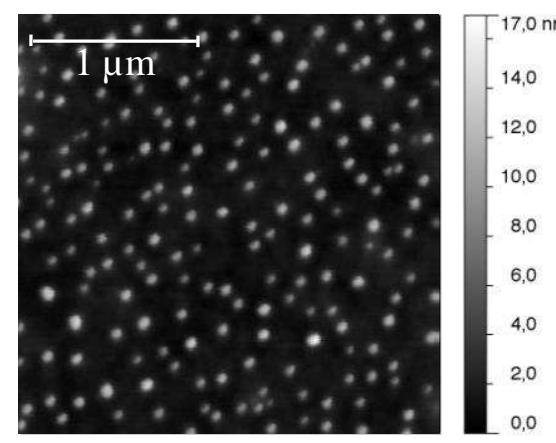

b)

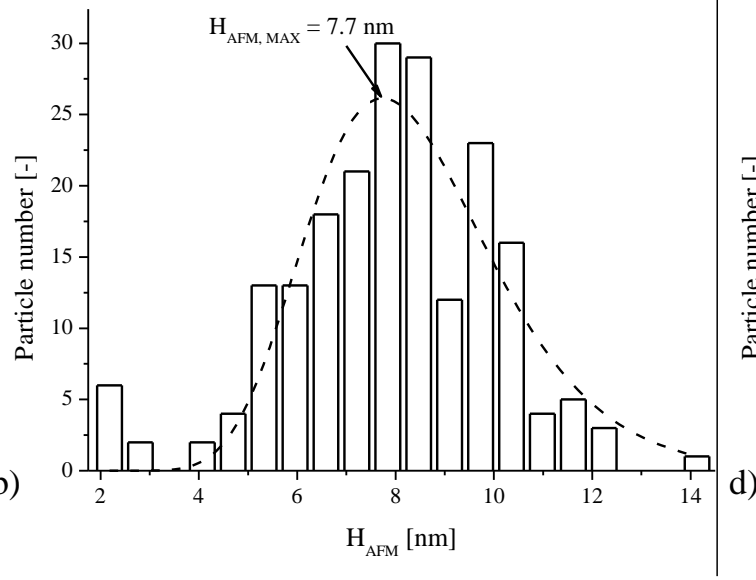

c)
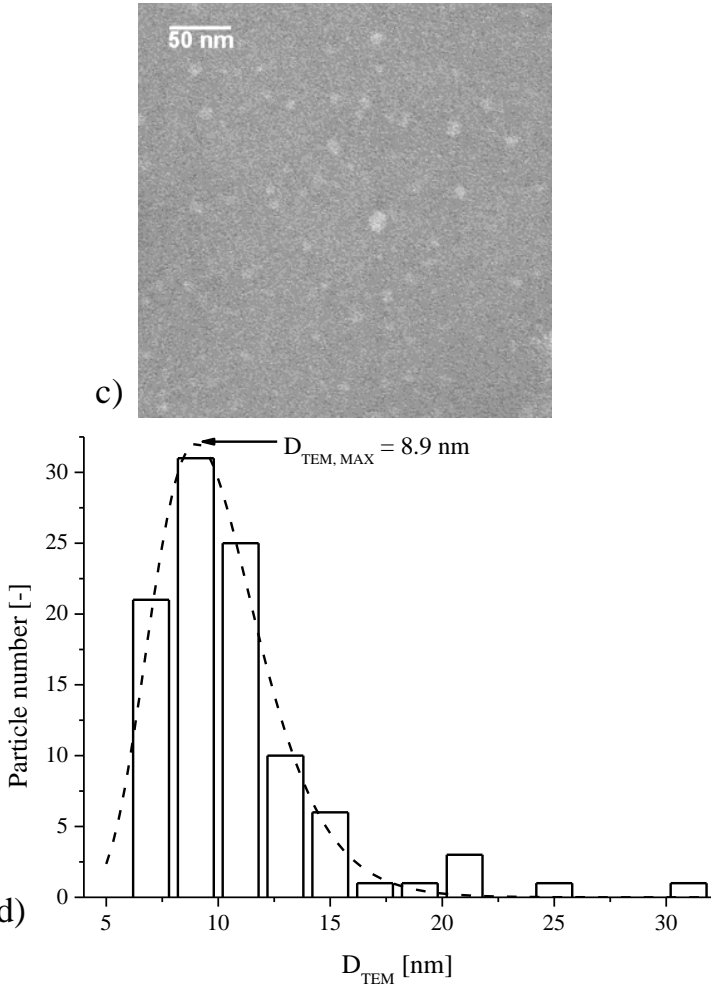

Figure 5. AFM: a) Topography image in tapping mode using a silicon tip, and b) corresponding height $\left(\mathrm{H}_{\mathrm{AFM}}\right)$ distribution after baseline correction and its fit using a lognormal distribution for T-MO-POx 25 at $0.04 \mathrm{mg} \mathrm{mL}^{-1}$ in water dropped onto a silica wafer. TEM: c) Image, and d) corresponding diameter ( $\left.\mathrm{D}_{\mathrm{TEM}}\right)$ distribution and its fit using a lognormal distribution for T-MO-POx 25 at $0.04 \mathrm{mg} \mathrm{mL}^{-1}$ in water dropped onto a glow discharged carbon coated copper grid in presence of uranyl actetate for contrast enhancement. 


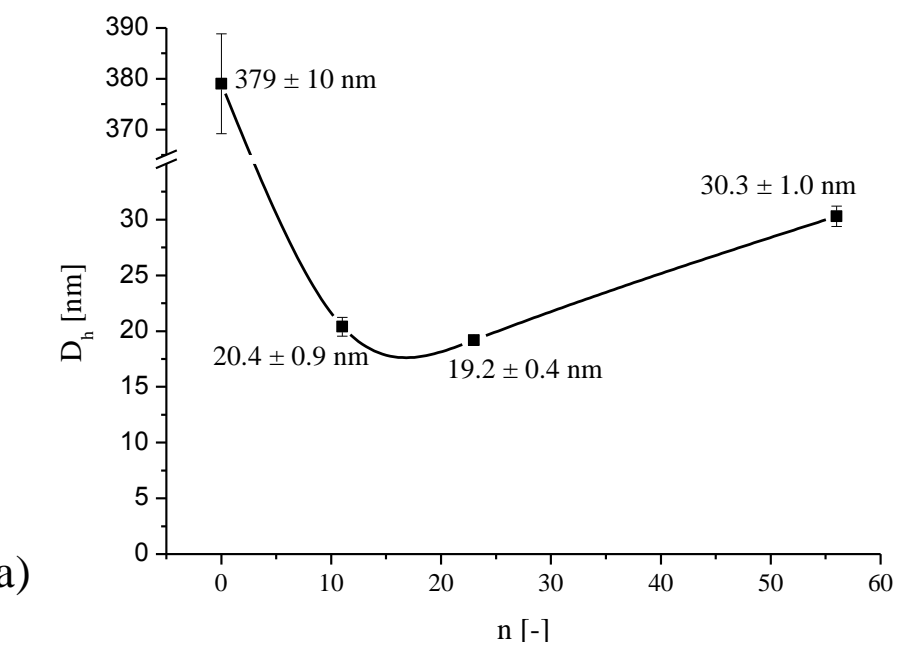

b)
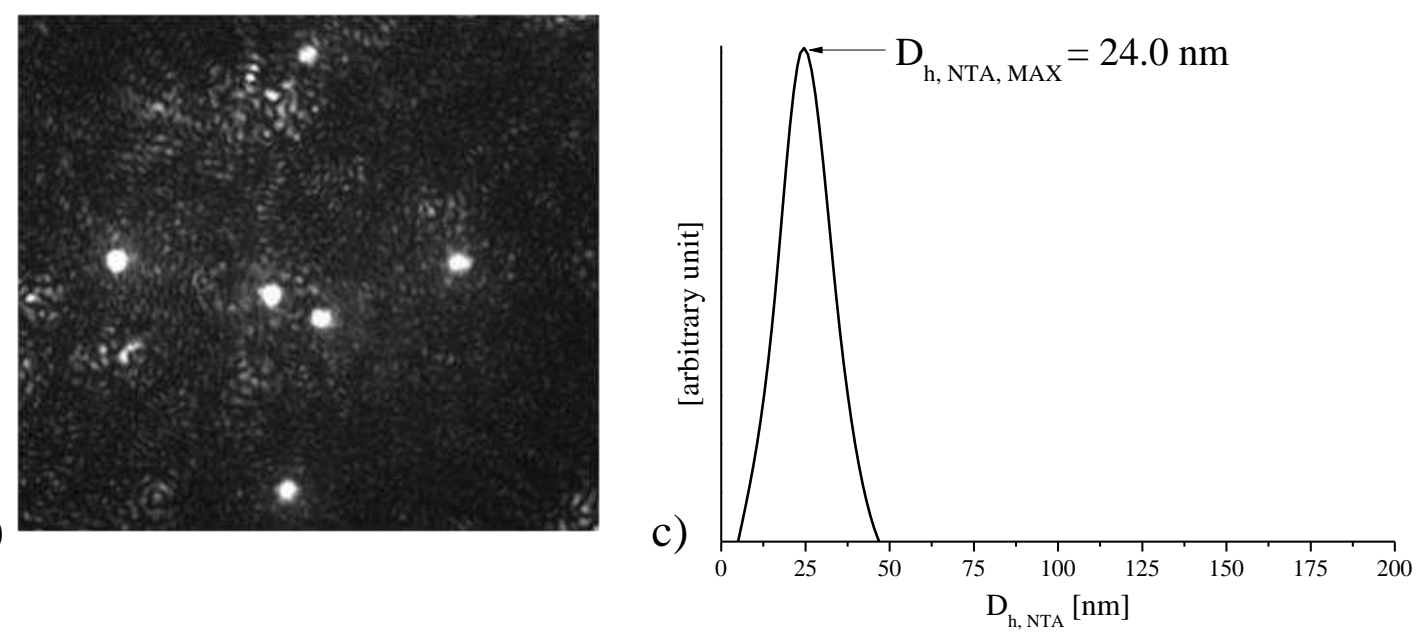

Figure 6. DLS: a) Dependence of the hydrodynamic diameter $\left(D_{h}\right)$ on the oxazoline monomer unit number (n) for Tri-GSO-POx $\mathrm{n}$ at $2 \mathrm{mg} \mathrm{mL}^{-1}$ in water. ${ }^{[79]} \mathrm{NTA}$ : b) Image taken from the video clip, and c) corresponding hydrodynamic diameter $\left(\mathrm{D}_{\mathrm{h}}, \mathrm{NTA}\right)$ distribution for Tri-GSO$\mathrm{POx}_{56}$ at $0.08 \mathrm{mg} \mathrm{mL}^{-1}$ in water. 
a)
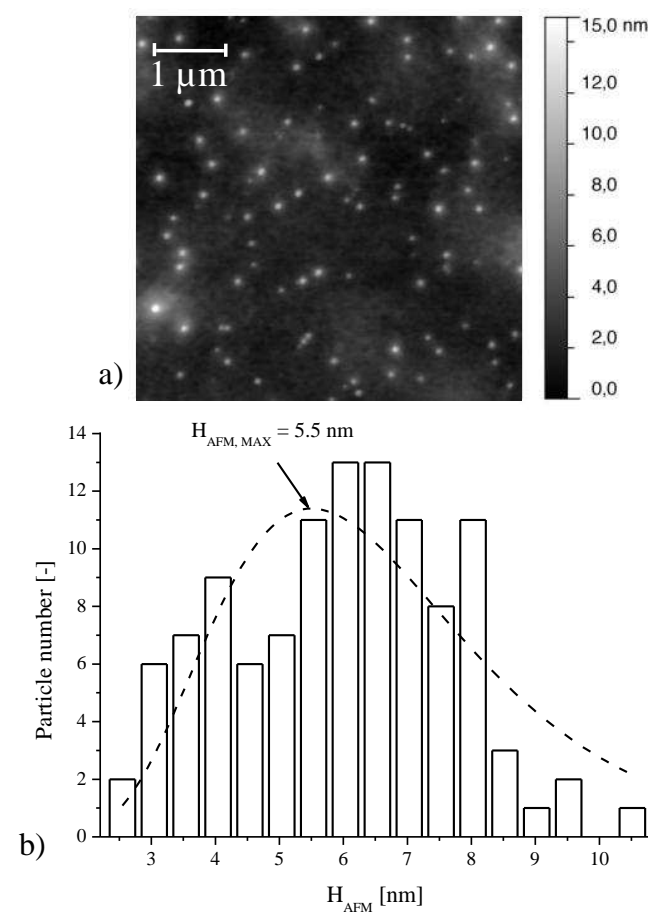

c)
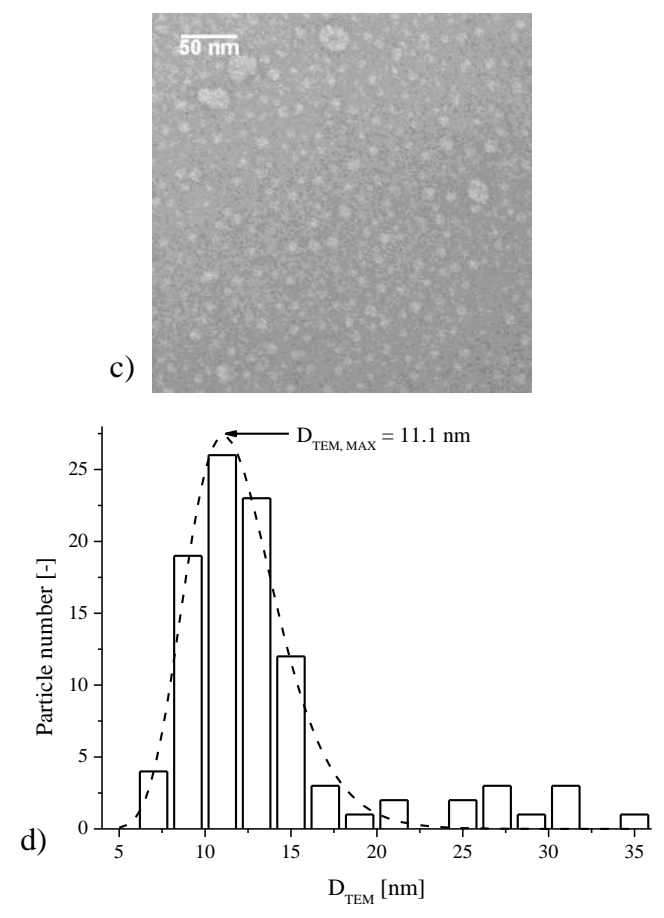

Figure 7. AFM: a) Topography image in tapping mode using a silicon tip, and b) corresponding height $\left(\mathrm{H}_{\mathrm{AFM}}\right)$ distribution after baseline correction and its fit using a lognormal distribution for Tri-GSO-POx 11 at $0.04 \mathrm{mg} \mathrm{mL}^{-1}$ in water dropped onto a silica wafer. TEM: c) Image, and d) corresponding diameter ( $\left.\mathrm{D}_{\mathrm{TEM}}\right)$ distribution and its fit using a lognormal distribution for Tri-GSO-POx 11 at $0.04 \mathrm{mg} \mathrm{mL}^{-1}$ in water dropped onto a glow discharged carbon coated copper grid in presence of uranyl actetate for contrast enhancement.

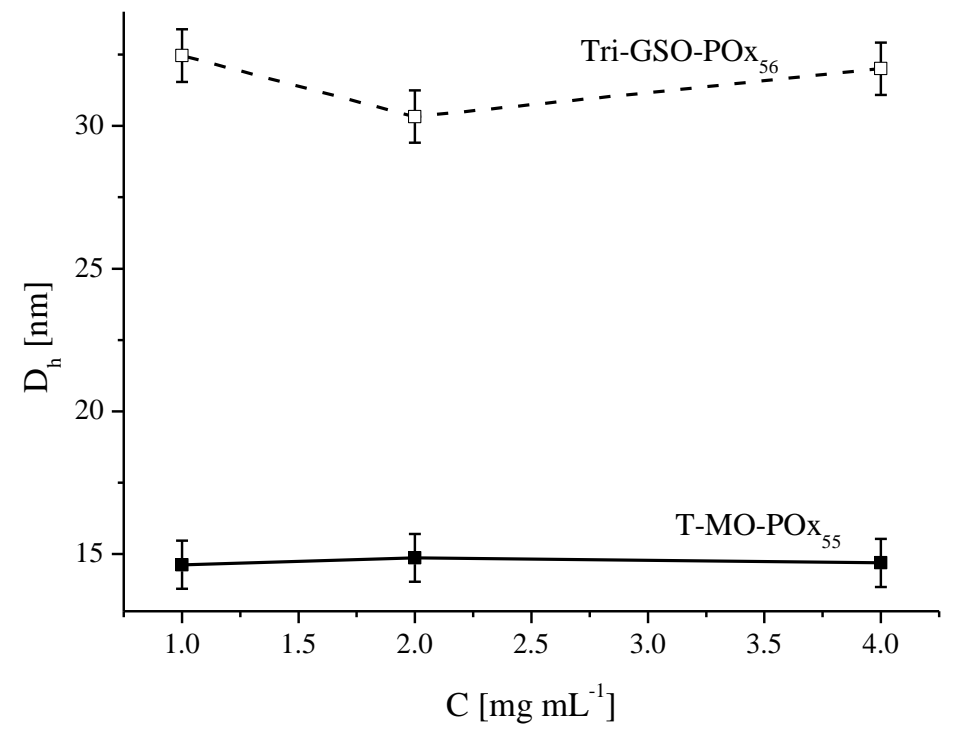

Figure 8. DLS: Dependence of the hydrodynamic diameter $\left(D_{h}\right)$ on the copolymer concentration (C) for T-MO-POx 55 and Tri-GSO-POx 56 at $2 \mathrm{mg} \mathrm{mL}^{-1}$ in water. ${ }^{[79]}$ 

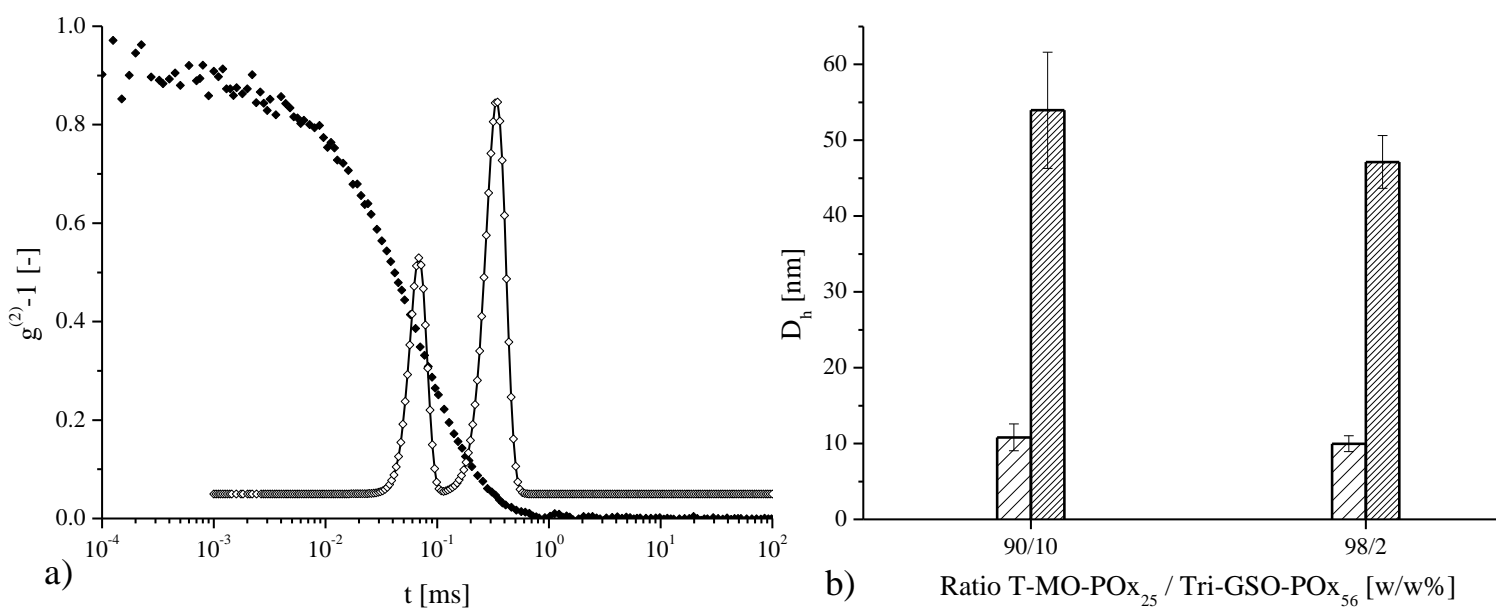

Figure 9. DLS: a) Autocorrelation function $\left(\mathrm{g}^{(2)}-1\right)$ and relaxation time distribution at a scattering angle of $90^{\circ}$ for a T-MO-POx 25 and Tri-GSO-POx ${ }_{56}$ mixture $(90 / 10 \mathrm{w} / \mathrm{w} \%)$ at a total concentration of $2 \mathrm{mg} \mathrm{mL}^{-1}$ in water. The deconvolution of the $\mathrm{g}^{(2)}-1$-function is successfully carried out using a double exponential function. b) Hydrodynamic diameter $\left(D_{h}\right)$ at a scattering angle of $90^{\circ}$ for $\mathrm{T}-\mathrm{MO}-\mathrm{POx}_{25}$ and Tri-GSO-POx ${ }_{56}$ mixtures at a total concentration of $2 \mathrm{mg} \mathrm{mL}^{-1}$ in water. ${ }^{[79]}$
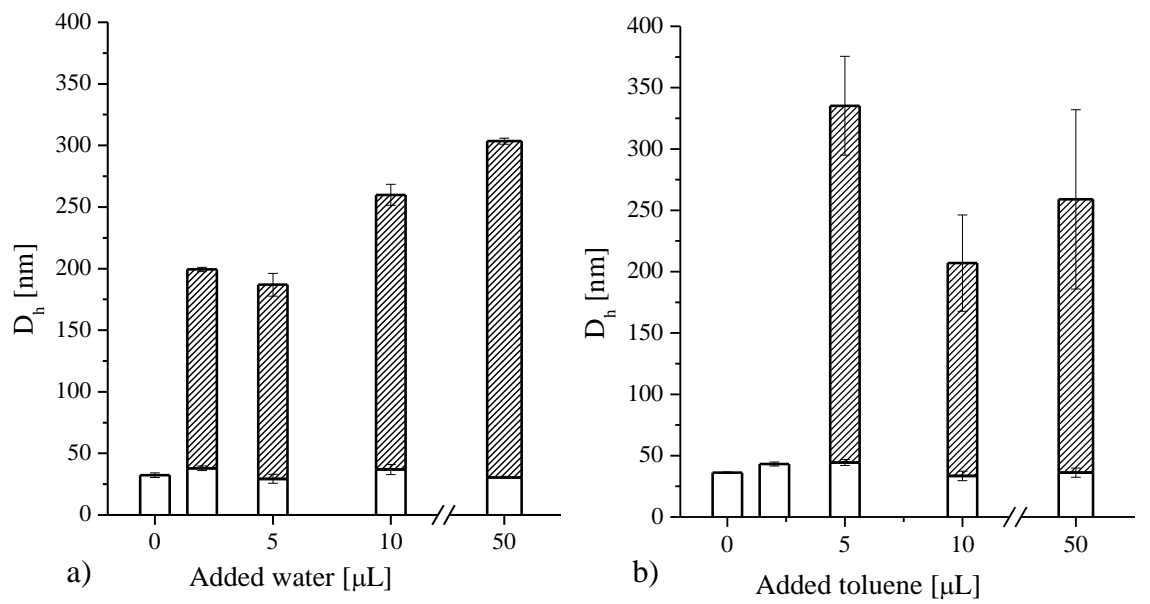

Figure 10. DLS: Hydrodynamic diameter $\left(D_{h}\right)$ at a scattering angle of $90^{\circ}$ for $1 \mathrm{~mL}$ of TriGSO-POx 56 : a) at $1 \mathrm{mg} \mathrm{mL}^{-1}$ in toluene, when a controlled volume of water is subsequently added, and b) at $2 \mathrm{mg} \mathrm{mL}^{-1}$ in water, when a controlled volume of toluene is subsequently added. ${ }^{[79]}$

\section{Table of contents:}




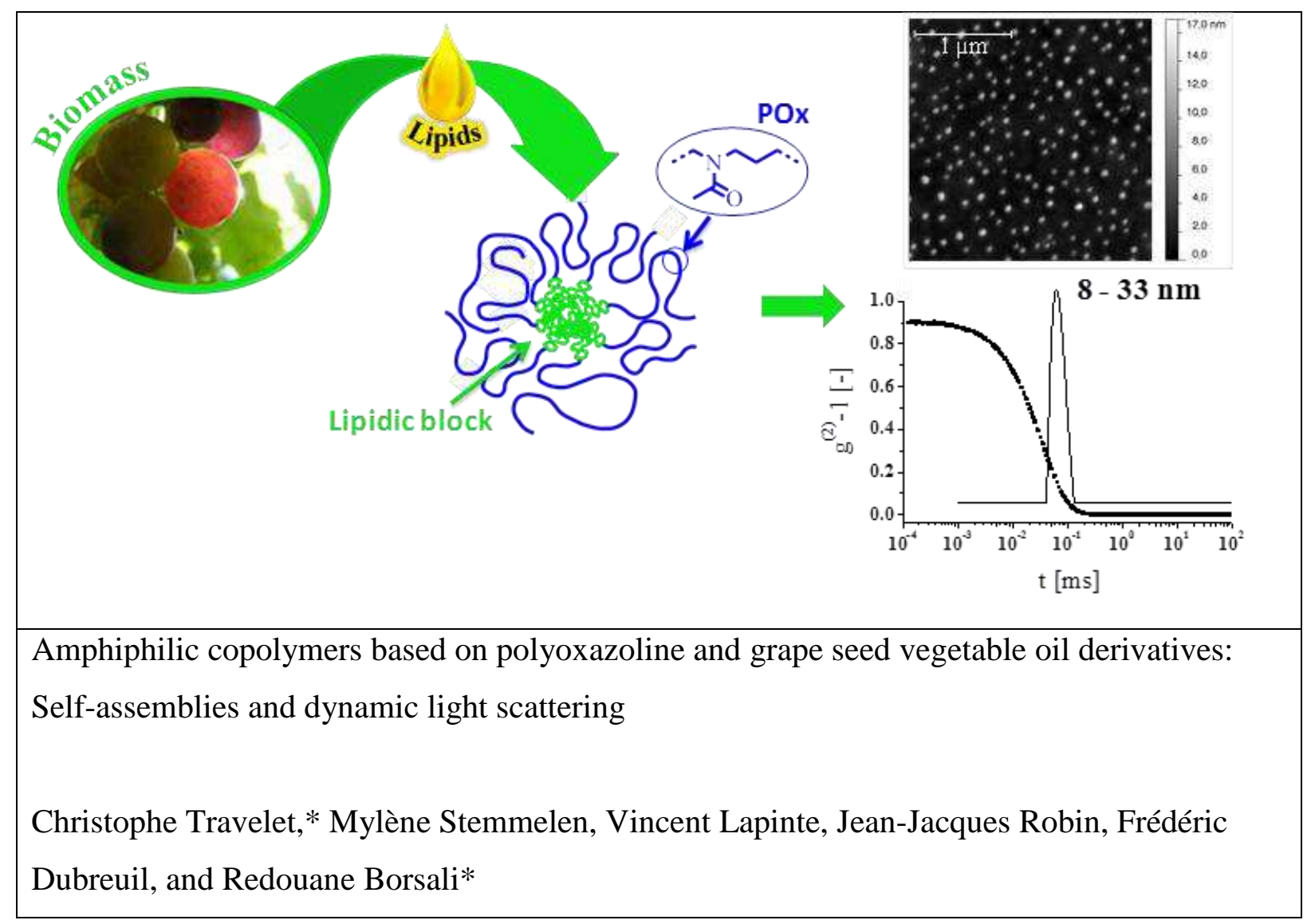

